\title{
A Review on Synthesis, Properties, of Liquid Crystal Dendrimers
}

\author{
Zinah H. Ali and Nasreen R. Jber*
}

Department of Chemistry, College of Science, Al-Nahrain University, Baghdad-Iraq

\begin{tabular}{|c|c|}
\hline Article's Information & Abstract \\
\hline $\begin{array}{l}\text { Received: } \\
09.11 .2021 \\
\text { Accepted: } \\
\text { 27.12.2021 } \\
\text { Published: } \\
31-12-2021\end{array}$ & \multirow{2}{*}{$\begin{array}{l}\text { This review provides brief information concerning with the dendrimer. The } \\
\text { supramolecular organization of selected examples of liquid-crystalline } \\
\text { dendrimers within lamellar, columnar and nematic phases is reported. It is shown } \\
\text { that tuning of the mesomorphic structure can be achieved by an appropriate } \\
\text { molecular design depending upon the chemical nature of the terminal mesogenic } \\
\text { groups, dendritic core and dendrimer generation. The pseudospherical shape of a } \\
\text { dendrimer arises from its structure, which consists of an internal region (the core) } \\
\text { which is connected to repeating units constituting a radial branching pattern. }\end{array}$} \\
\hline $\begin{array}{l}\text { Keywords: } \\
\text { Liquid crystal } \\
\text { Dendrimers synthesis }\end{array}$ & \\
\hline $\begin{array}{l}\text { DOI: } 10.22401 / \text { ANJS.24.4.03 } \\
{ }^{*} \text { Corresponding author: Nasreer }\end{array}$ & $@$ nahrainuniv.edu.iq \\
\hline
\end{tabular}

\section{Introduction}

Dendrimers are nanosized branched molecules composed of a central core with dendrons extending outward, similar to tree branches [1]. The dendrimer molecules are designed to have a uniform molecular weight and size according to their generation number. The dendrimer molecules are designed to have a uniform molecular weight and size according to their generation number. The terminal groups on the exterior can be chemically modified or tailored according to the desired application [2]. Dendrimers can encapsulate cargos or be chemically attached to different molecules according to the size, surface properties, and functional groups present, and thereby protect these molecules against the adverse effects of external factors. Furthermore, they can release these molecules within their targeted environment. Since the synthesis of "cascade" molecules by Vögtle et al. in 1978 [3], several different synthetic methodologies for a variety of different kinds of dendrimers have been developed. In general, their construction relies on two approaches, described as divergent and convergent.

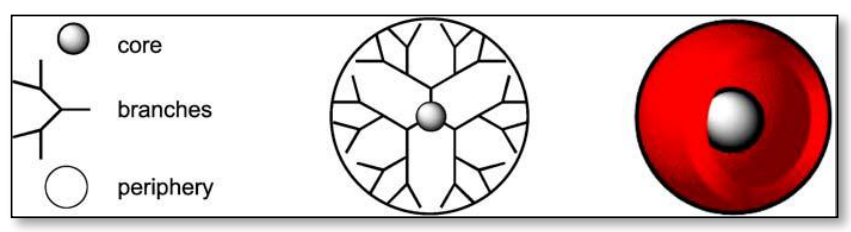

Figure 1. Two and three-dimensional representations of dendrimers

\section{History of Dendrimers}

Dendrimers are an attractive exclusive class of polymers with controlled structure. A dendrimer is both a covalently assemble molecule and also a distinct nanoparticle. The first dendrimers be completed by divergent synthesis advanced by Fritz Vogtle in 1978, [3] R.G. Denkewalter at Allied Corporation in 1981, [4] Donald Tomalia at Dow Chemical in 1983 and in 1985 [5].

\section{Synthesis}

General methods of dendrimer synthesis: dendrimers can consider three major parts i.e. a core, an inner shell, and an outer shell. A dendrimer can be generating by varying functionality in each of this portion to categorize properties such as solubility, thermal stability, and addition of compounds for meticulous application. Synthetic procedure can also correctly manage the size and number of branches on the dendrimer. There are two different methods of dendrimer synthesis, divergent synthesis and convergent synthesis [6].

\subsection{Divergent method:}

The dendrimer is assembling to from a multifunctional core, which is extended outward by a sequence of reactions, commonly a Michael addition reaction. Each step of the reaction must be determined to full completion to prevent mistakes in the dendrimer, which can ground trailing generations (some branches are shorter than the others). Such impurities can collision the functionality and symmetry of the dendrimer, but are tremendously difficult to purify out because the relative size variation between perfect and imperfect dendrimers is very small. The major disadvantage of this approach is that the incomplete growth and the side reactions lead to imperfect dendrimers. To minimize these side reactions and imperfections, it's recommended to use a large excess of reagents. The divergent growth reaction of dendrimer can be shown in. 


\section{Al-Nahrain Journal of Science}

ANJS, Vol.24 (4), December, 2021, pp. 15-25

\subsection{Convergent method:}

Dendrimers are constructed from beginning of small molecules that end up at the surface of the sphere, and reactions precede inmost building inward and are eventually attached to a core. This method makes it very much easier to eliminate impurities and shorter twigs along the way, so that the final dendrimer is more mono-disperse. However, dendrimers ended this way are not as large as those made by divergent methods because crowding due to stearic property along the core is restrictive [7]. The convergent growth reaction of dendrimer can show in Figure 2. Main problem of convergent method is that we cannot manufacture a large molecule for drug loading due to crowding and stearic effect [7].

\subsection{Click chemistry:}

Dendrimers have been prepared via click chemistry, employing Diels-Alder reactions [8] thiol-yne reactions and azide-alkyne reactions [9]. Click chemistry was first introduced by K. Barry Sharpless of the Scripps Research Institute in 2001 and describe chemistry modified to engender substances rapidly and consistent by combination of small units collectively. It is not a solitary reaction, but was intended to imitate nature, that can also generate molecules by joining small modular units [10].

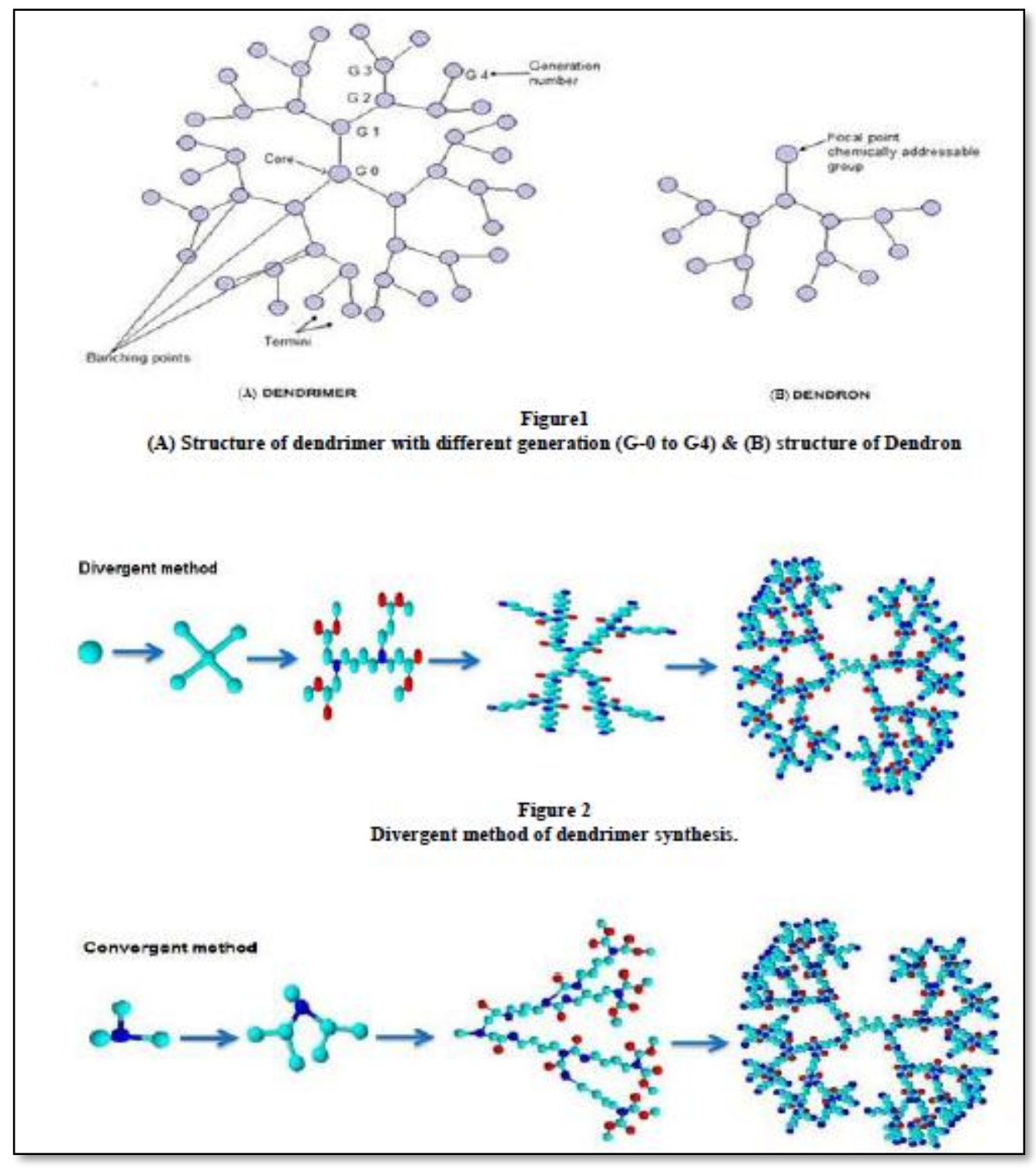

Figure 2. Convergent method of dendrimer synthesis [10].

\section{Factors Affecting Dendrimers Synthesis}

There are different factors which can affect dendrimer synthesis. The non-ideal dendrimer expansion may be manifested through a variety of ways which includes:
1. Incomplete addition reaction.

2. Intermolecular cyclization.

3. Fragmentation.

4. Solvolysis of terminal functionalities. 


\section{Al-Nahrain Journal of Science}

ANJS, Vol.24 (4), December, 2021, pp. 15-25

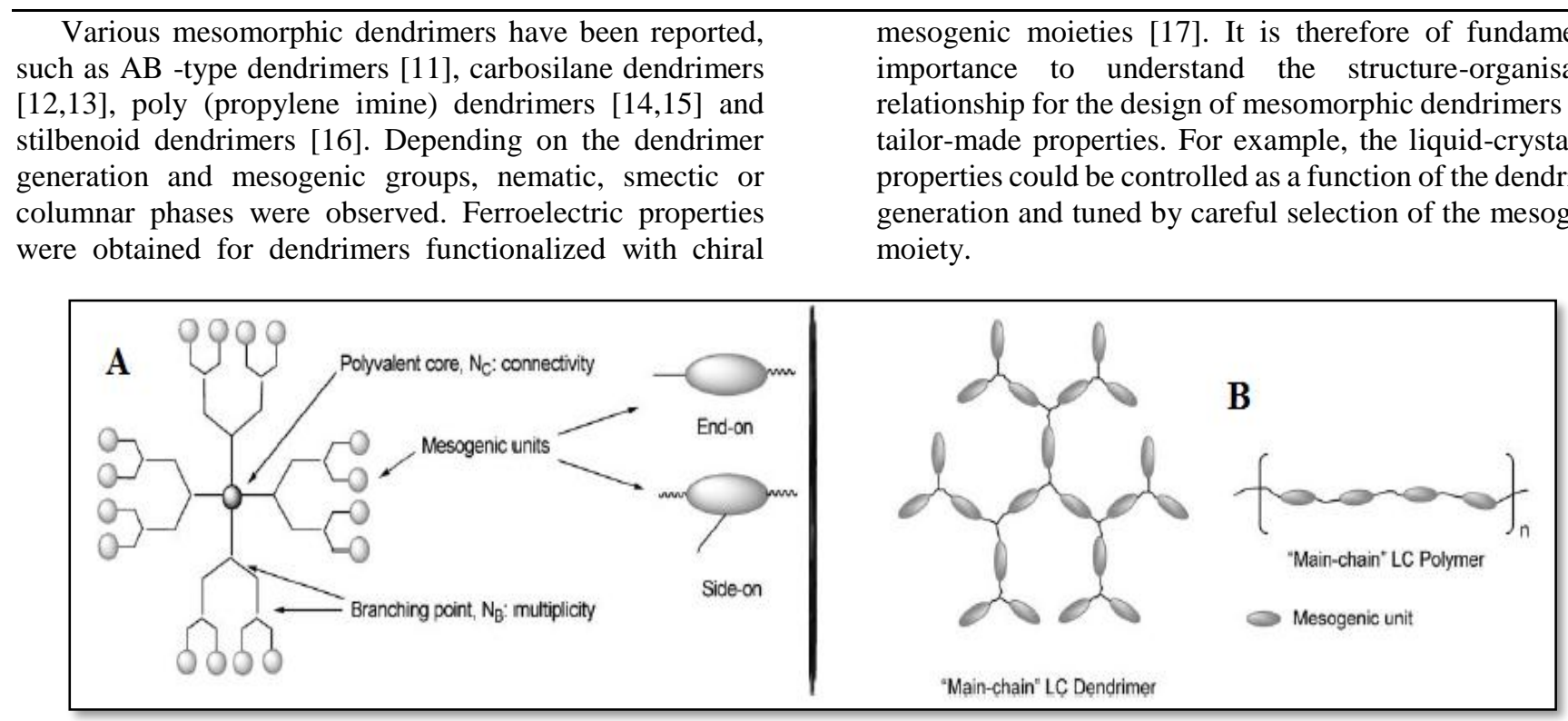

Figure 3. A: Schematic parts of a liquid crystal dendrimer. B: Schematic structure of “main-chain”' LC dendrimers [17].

\section{Literature Review}

\subsection{Synthesis of magnetic polyamidoamine dendrimers} [18]:

Zhoua, Q.; et.al. reported the synthesis of magnetic or magnetically modified materials play a key role in MSPE. Magnetite nanoparticles (MNPs) are usually used as the core materials. To increase the enrichment factor, MNPs often must be modified or functionalized with various materials, such as metal-organic frameworks (MOFs), carbon nan- otubes, graphene, and polymer materials. Polyamidoamine (PAMAM) dendrimers have received wide interest in the past few decades due to its special structure and properties. PAMAM dendrimers earn threedimensional (3D), monodispersed, highly branched, and symmetrical structures. Thus, they have been employed in many fields, such as gene diagnosis, drug delivery, and ultrasensitive sensors [19], PAMAM dendrimers and its deco- rated materials have been used to adsorb $\mathrm{Cu}^{2+}, \mathrm{Pb}^{2+}$, $\mathrm{Cr}^{2+}, \mathrm{Ni}^{2+}, \mathrm{Zn}^{2+}, \mathrm{Cd}^{2+}$, and $\mathrm{Hg}^{2+}$ [3].for the synthesis of, 80 mg of magnetic PAMAM dendrimers, aqueous sample with OCPs spiked at $20 \mu \mathrm{g} / \mathrm{L}, \mathrm{NaCl}$ to $25 \%(\mathrm{~W} / \mathrm{V})$, ethanol, and methanol then, $50 \mu \mathrm{L}$ was taken for HPLC analysis.

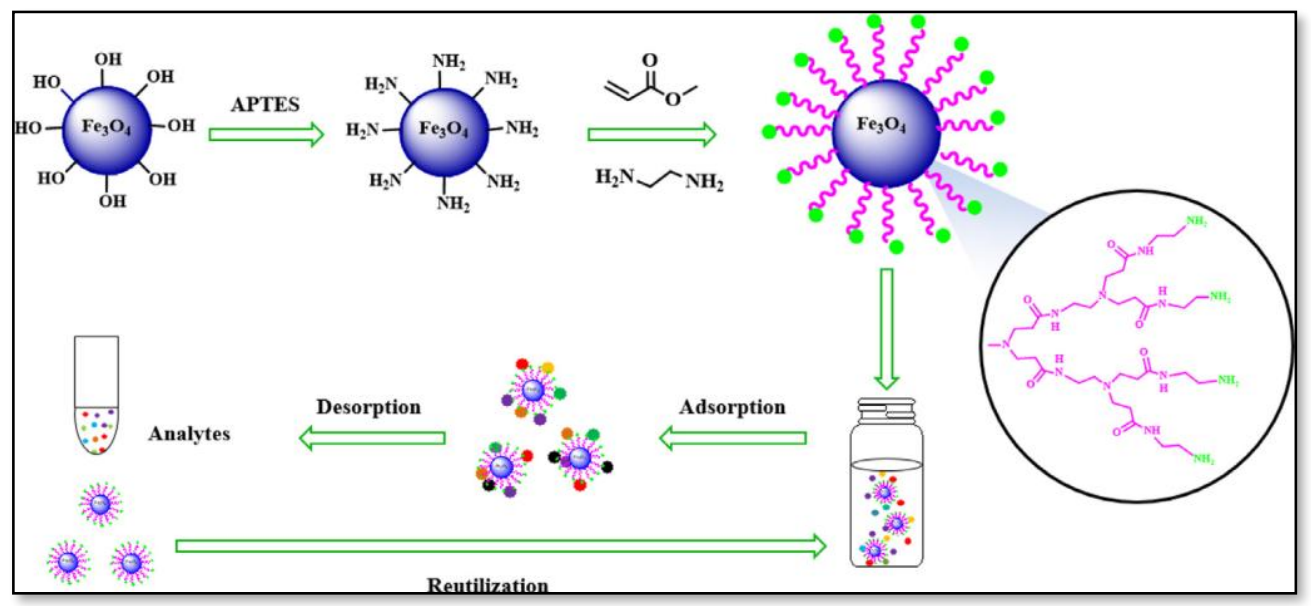

Figure 4. Synthetic procedure of MNPs-Gn and representative MSPE procedure [18].

\subsection{Anchoring and molecular conformation of new liquid crystalline dendrimer synthesized [20]:}

Aya, S.; et.al. reported the synthesis of Azo dendrimer, is a class of branched polymer, whose structure can bemodulated by light irradiation. Li et al. reported a mass migration phenomenon by a photo responsive version of the dendrimer, azo dendrimer [21], where azo benzene groups are linked to the mesogenic arms. They found that a spincoating film of the azo dendrimer can change the surface properties by shining light. Later, some investigations on 


\section{Al-Nahrain Journal of Science}

ANJS, Vol.24 (4), December, 2021, pp. 15-25

the liquid crystal anchoring behavior were made [22-24]. As applications of the materials, Momoi et al. demonstrated the development of LC alignment layer in the homeotropic

alignment model, taking advantage of the no need of the pre-surface treatment [25-27].

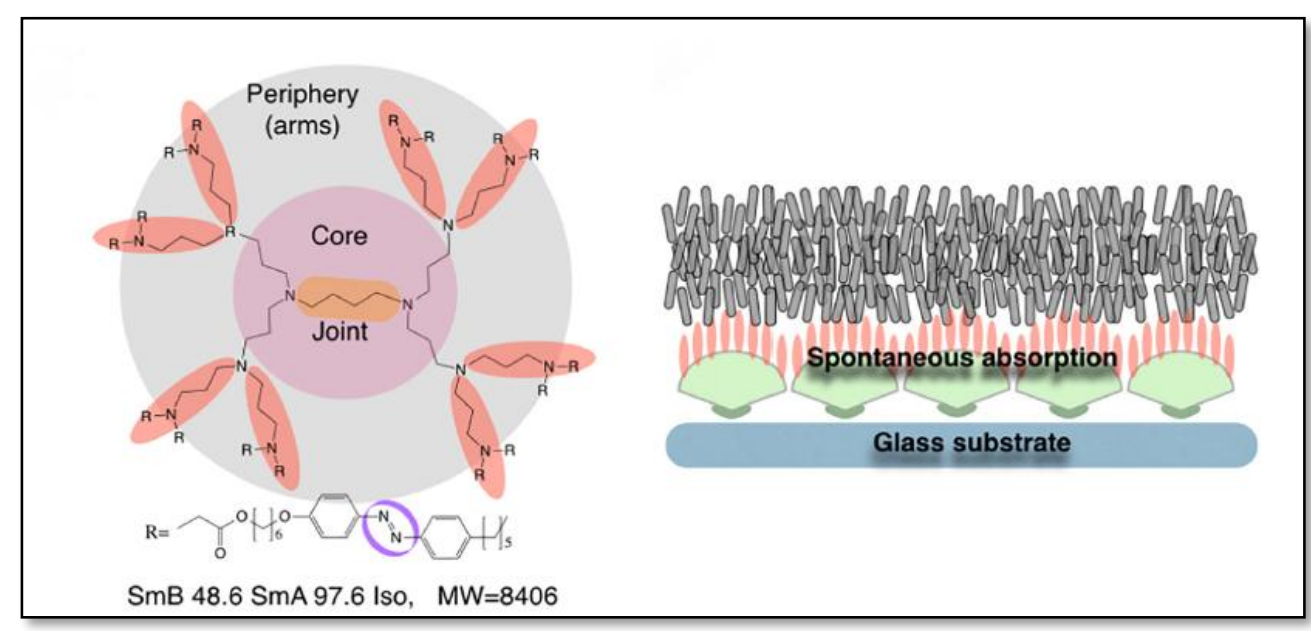

Figure 5. The structure of liquid crystalline dendrimer [21].

All the optical measurements were made in home-made liquid crystal cells, whose thickness is uncontrolled or controlled between $2 \mu \mathrm{m}$ up to $100 \mu \mathrm{m}$ by glass beads or plastic films. We used polarized light microscopes (POM; $\mathrm{BX} 53 \mathrm{P}$ and $\mathrm{BH} 2$, Olympus) to characterize the textures of the samples.

\subsection{Synthesis of new dendrimers containing carbazole with liquid crystalline, optical and electrochemical properties [28]:}

Novel liquid crystalline Janus dendrimers that combine a mesogenic block and an electroactive block have been synthesised. The mesogenic block is based on two thirdgeneration Percec-type dendrons bearing six or eight terminal dodecyloxy alkyl chains, whereas the electroactive blocks are formed by one or two carbazole units [29].

Iguarbe, V. et al. reported the synthesis of the Percectype mesogenic units, were prepared by a previously described method [30]. The synthesis of the Janus dendrimers was carried out by the coupling of the mesogenic block and carbazole-containing. units by esterification reaction with DCC catalysed by DPTS in dry dichloromethane [31].

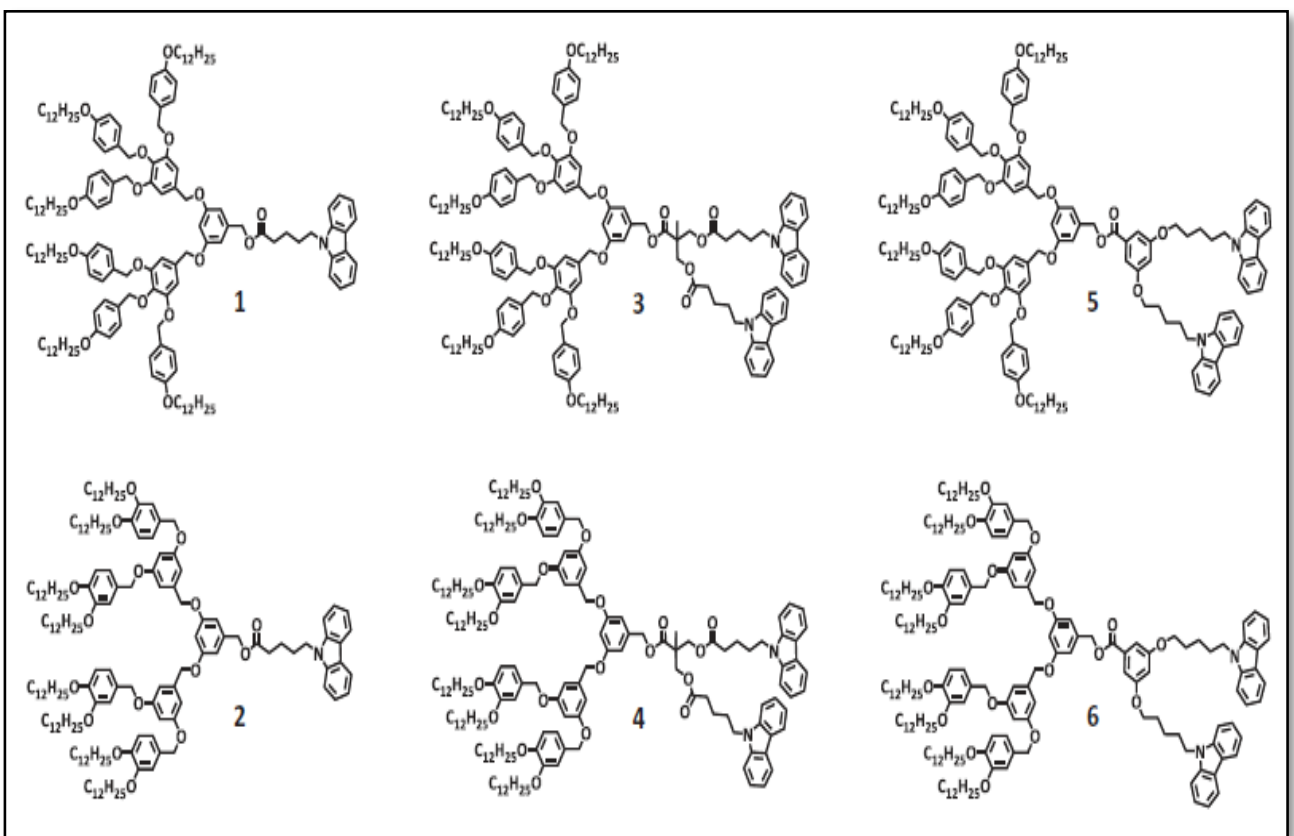

Figure 6. Chemical structures of the Janus dendrimers. 


\section{Al-Nahrain Journal of Science}

ANJS, Vol.24 (4), December, 2021, pp. 15-25

\subsection{Ferrocenyl phosphorhydrazone dendrimers synthesis, and electrochemical and catalytic properties [32]:}

Turrin, C. O.; et al. reported the discovery of ferrocene is often associated with the rapid growth of organometallic chemistry. Dendrimers are highly branched macromolecules that can be functionalized at will at all levels of their structure. The functionalization of dendrimers with ferrocene derivatives can be carried out easily as terminal functions on the surface, but also at the core, or at one or several layers inside the structure. This review will focus on phosphorhydrazone dendrimers functionalized with ferrocene derivatives, on the surface, at the core, at all layers or within a single layer inside the structure [33].

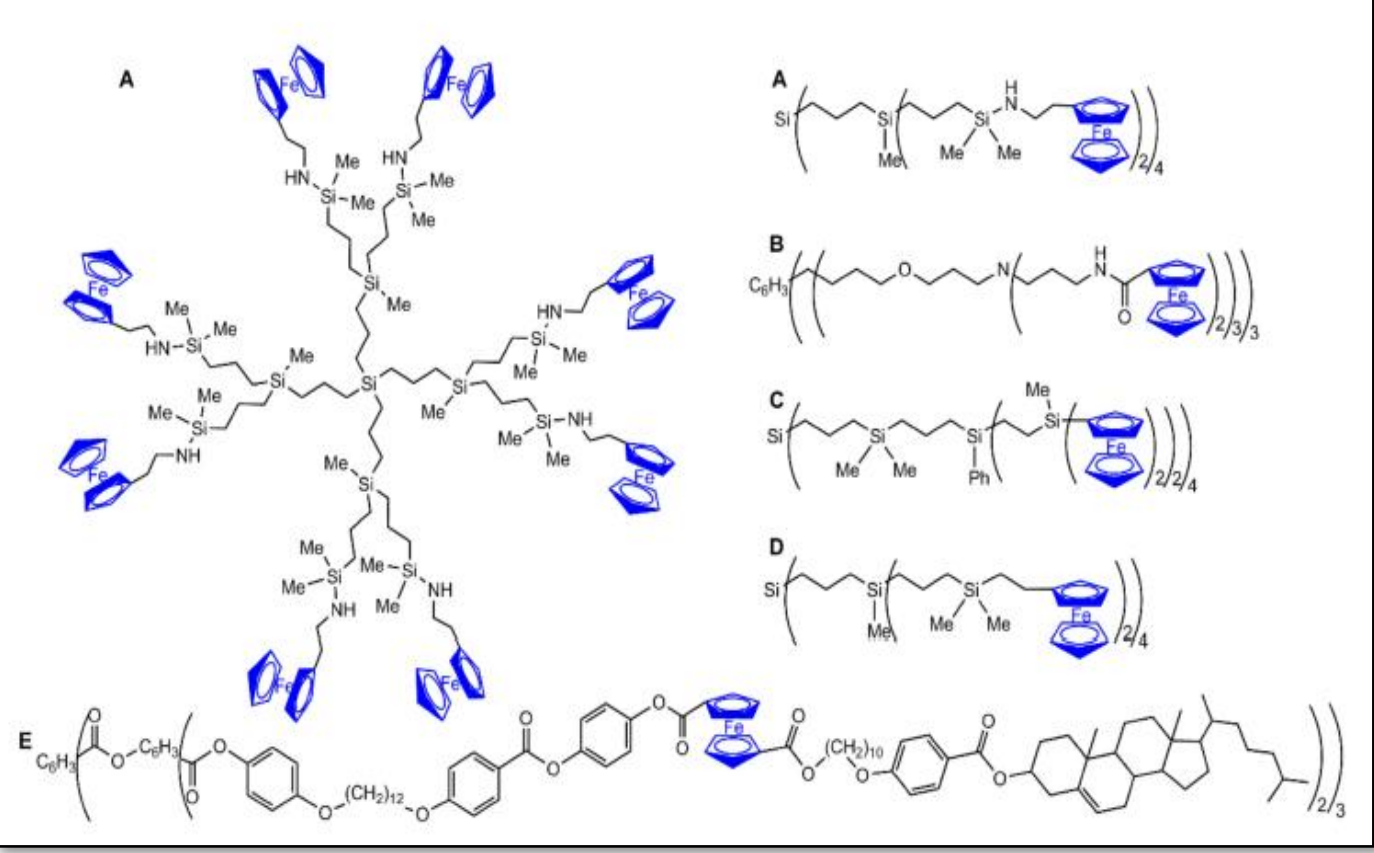

Figure 7. Early examples of ferrocenyl dendrimers. Dendrimer A is drawn two times: the full structure is on the left and the linear structure is on the right. The other dendrimers (B to E) are drawn linearly [33].

5.5 New Poly (amidoamine) dendrimers: covalent and supramolecular synthesis [34]:

Lyu, Z.; et al. reported the synthesis of poly(amidoamine) (PAMAM) dendrimers are the most extensively studied by virtue of their readily availability via robust synthesis as well as their dendritic structure and peptide/protein mimic features. Since the seminal report by Tomalia et al.; various strategies have been made available for PAMAM dendrimers, including divergent and/or convergent synthesis alongside click chemistry [35] 


\section{Al-Nahrain Journal of Science}

ANJS, Vol.24 (4), December, 2021, pp. 15-25

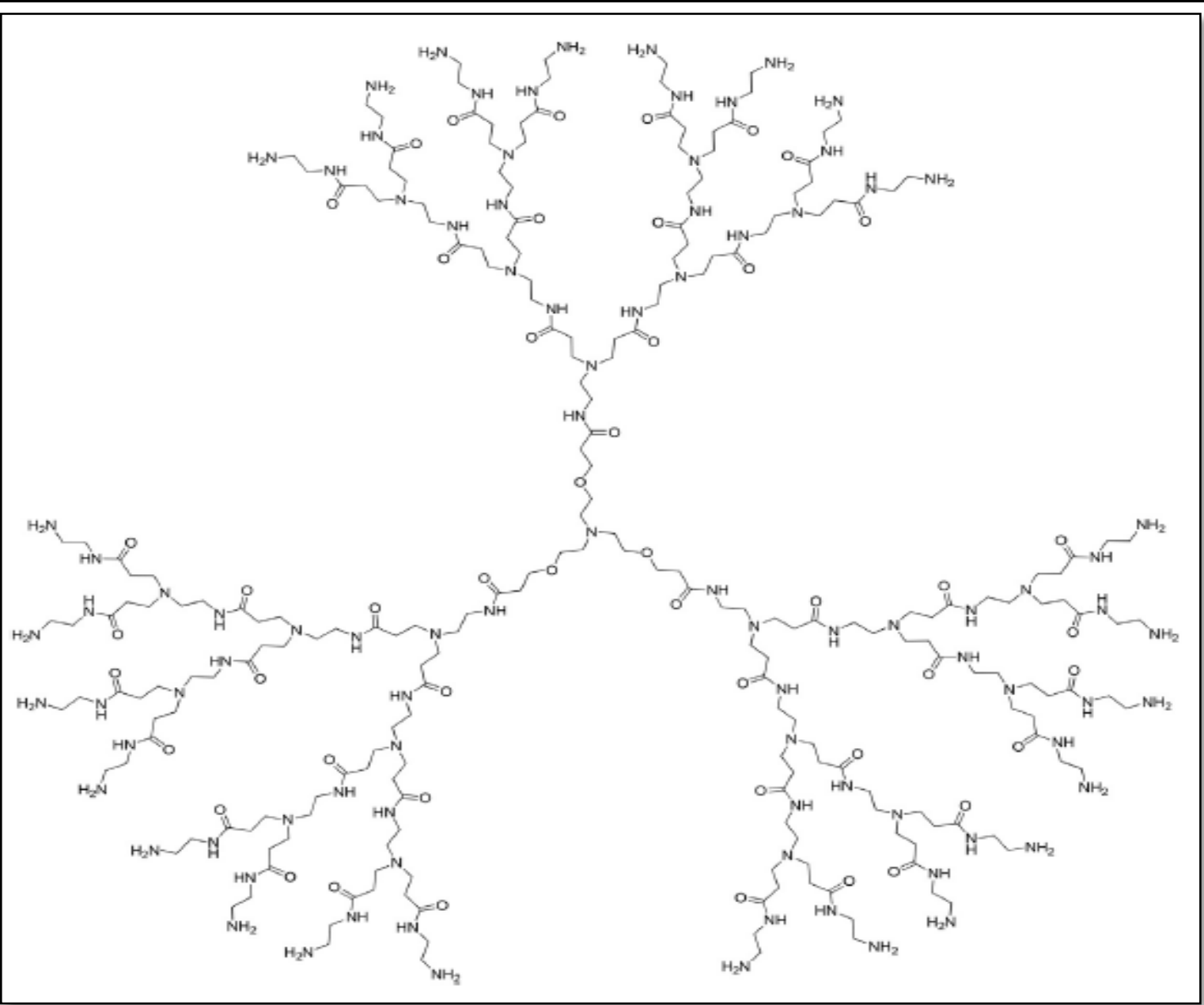

Figure 8. Chemical structure of a 3rd generation of poly(amidoamine) (PAMAM) dendrimer bearing a triethanolamine-core [36].

\subsection{Proton-conductive materials formed by coumarin photo crosslinked ionic liquid crystal dendrimers [37]:}

A new family of liquid crystalline dendrimers have been synthesized by ionic self-assembly of poly(amidoamine) (PAMAM) dendrimers bearing 4, 8, 16, 32 or $64 \mathrm{NH}_{2}$ terminal groups and a coumarin-containing bifunctional dendron. The noncovalent architectures were obtained by the formation of the ionic salts between the carboxylic acid group of the dendron and the terminal amine groups of the PAMAM dendrimer. Nanostructured LC phases can be stabilized by photopolymerization to maintain the anisotropic ion transport over a longer period of time.
Crosslinking of polymerizable LC monomers in their mesophase can yield nanostructured, thermally and mechanically stable membrane materials with permanent pathways for ion transport [38].

Concellón A.; et.al. reported the synthesis Ionic dendrimers were prepared by mixing a tetrahydrofuran (THF) solution of Ac-ChCou with a solution of the corresponding generation of PAMAM dendrimer in the stoichiometry necessary to functionalize all terminal amine groups. The mixture was ultrasonicated for $5 \mathrm{~min}$, THF evaporated and the sample dried. The formation of ionic interactions between the PAMAM dendrimer and the dendron acids. 


\section{Al-Nahrain Journal of Science}

ANJS, Vol.24 (4), December, 2021, pp. 15-25

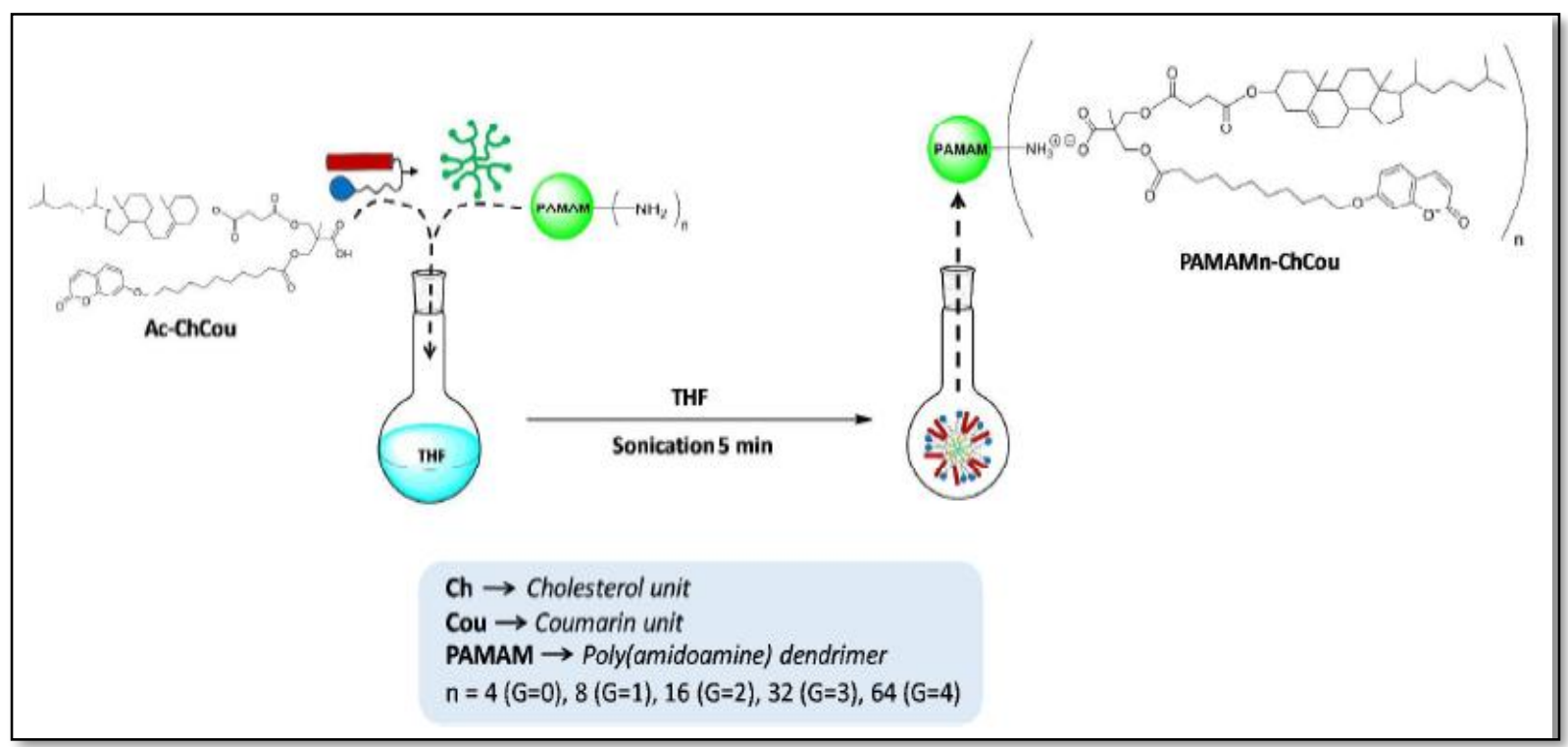

Figure 9. Schematic representation of the ionic self-assembly process to prepare the ionic LC dendrimers and the nomenclature of the ionic dendrimers [38].

\subsection{Synthesis of Azodendrimers as a photoactive interface for liquid crystals [39]:}

Dendrimers with azo moieties in their peripherals (azodendrimers), which we developed, are useful as a photoactive interface for liquid crystal (LC) systems. Azo molecules have been widely used for manipulating LC orientation [40] or even inducing phase. transitions by light irradiation [41]. These changes are driven by the photoisomerisation. The azodendrimers are dissolved in an LC host or the substrate surfaces are modified by them. We developed azodendrimers (dendrimers with azo moieties) for advanced optical applications [42].

We developed a variety of mesogens in the peripheries such as biphenyls in addition to azobenzenes. We refer the LC dendrimers as DG-nX, where $\mathrm{G}$ is the generation of the dendrimer, $\mathrm{n}$ is the number of carbon atoms of the alkylene spacer in the mesogenic unit and $X$ represents the mesogenic structure. Numbers after $X$ represent the numbers of carbon atoms at the end of the mesogenic group. All dendrimers exhibit smectic (mostly SmA) LC phases.

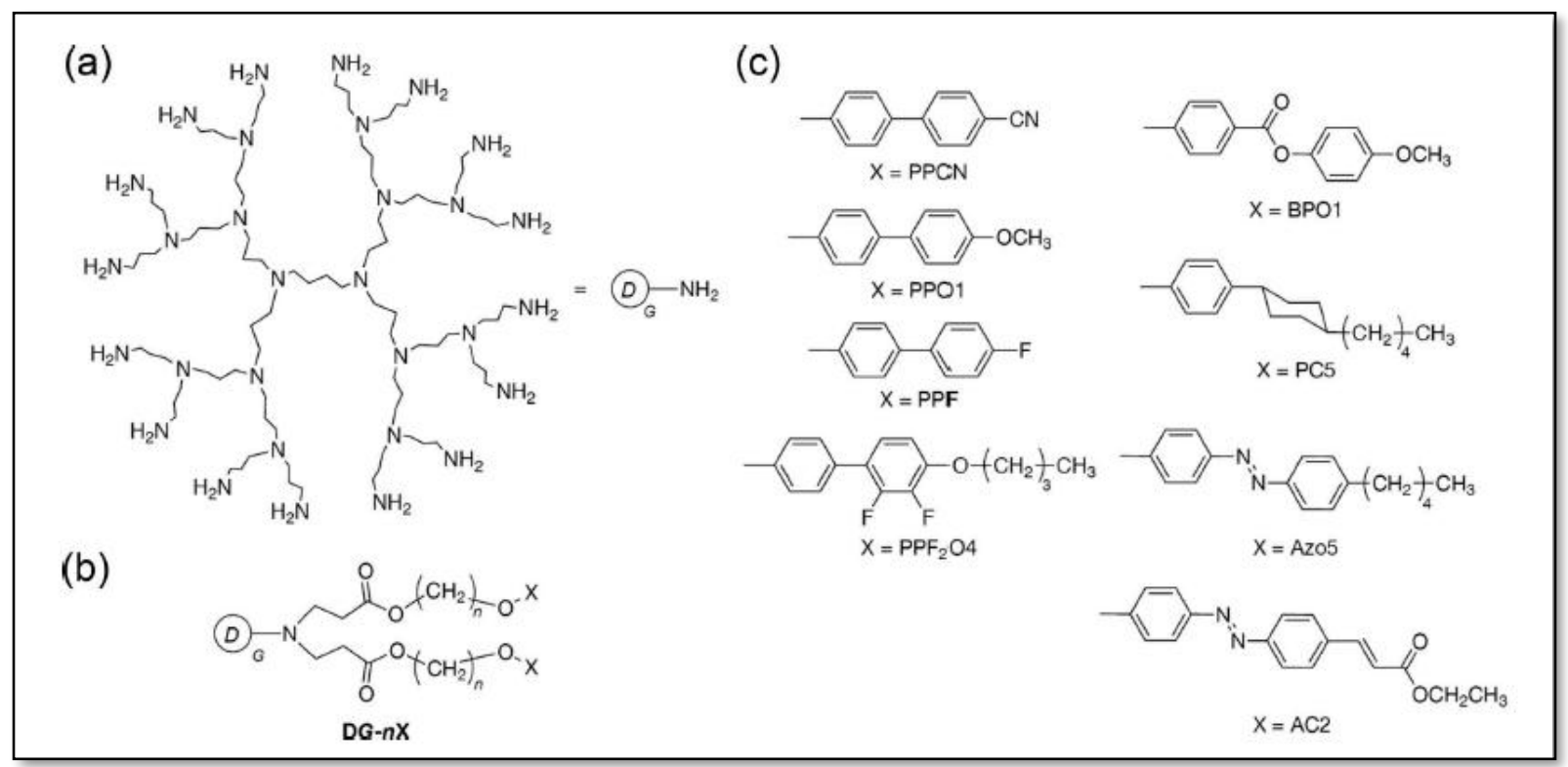

Figure 10. (Colour online) Chemical structures of (a) a poly(propyleneimine) dendrimer, (b) its peripheral and (c) mesogenic groups at the end of the peripheral. The dendrimers are designated as DG- $n X$, where $\mathrm{G}$ is a generation, $\mathrm{n}$ is a number of carbons of the methylene group and $\mathrm{X}$ is each mesogenic group shown in (c). Numbers after $\mathrm{X}$ represent the number of carbon atoms at the end of the mesogenic groups. 


\section{Al-Nahrain Journal of Science}

ANJS, Vol.24 (4), December, 2021, pp. 15-25

\subsection{Liquid crystalline dendrimer; Synthesis and Characterization [43]:}

A new family of nematic liquid crystal dendrimers derived from 3,5 dihydroxybenzoic acid were synthesized. The synthesis of the dendrimers compounds shows the influence of the dendritic core on the mesomorphic properties [44].
Jber, N. R.; et.al. reported the synthesis of new liquid crystal by dissolve ( $1 \mathrm{~g}, 0.006$ mole) of 3,5- dihydroxy benzoic acid in $(5 \mathrm{ml})$ of pyridine, then add compound $(3,5-$ Bis-[3 ,5 -di-(4“'-nitrophenyl-4“'ethylene-1,2-dioxy) phenylimine] benzoylchloride for four hours in an ice bath then two drops of $\mathrm{HCl}$ to get precipitation then filtered to give precipitation of $\mathrm{G} 3$.

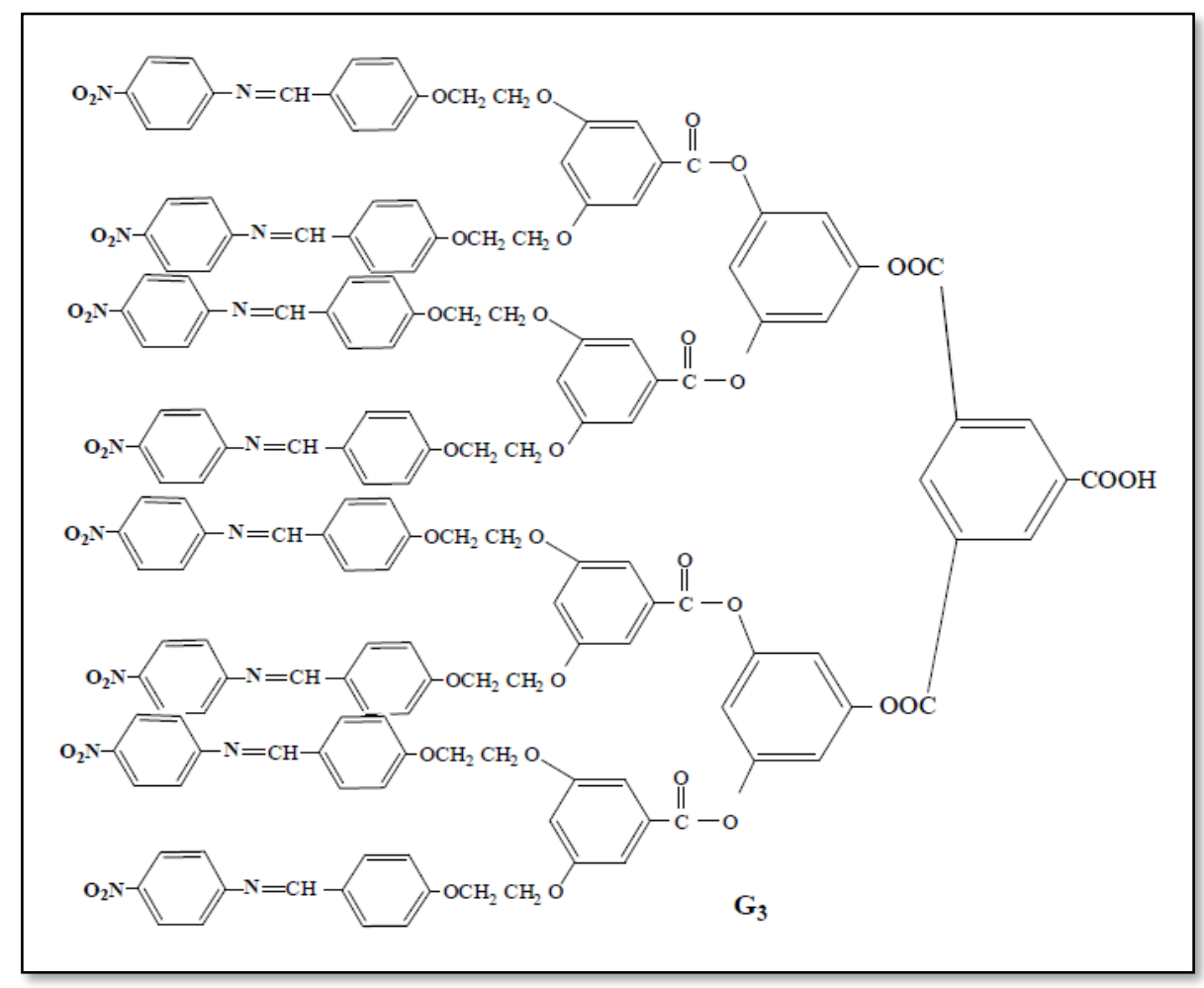

Figure 11. The new liquid crystal dendrimer that synthesized.

\subsection{Synthesis of Columnar Phases in Liquid Crystal Dendrimers [45]:}

Liquid crystal dendrimers are formed by attaching mesogenic units to a dendritic core via flexible spacer units. They provide an interesting example of the nanoscale structures formed by two antagonistic influences. X-ray diffraction has been done at elevated pressure on the third and fifth generation of a series of liquid crystal dendrimers that have already been extensively studied at ambient pressure [46]. Some of the hydrogen sites in the phenyl rings were deuterated because the materials were originally made for a neutron scattering study but this does not influence the phase behaviour or transition temperatures. The thirdgeneration dendrimer was a 50:50 mixture of normal hydrogenous molecules and one with the inner phenyl ring deuterated and will be designated G3HD. Its transition temperatures and phase structure from $\mathrm{X}$-ray diffraction were reported previously to be $\mathrm{Cr} 20{ }^{\circ} \mathrm{C} \mathrm{C} \mathrm{Sm} \mathrm{A} 108{ }^{\circ} \mathrm{C} \mathrm{I}$ 


\section{Al-Nahrain Journal of Science}

ANJS, Vol.24 (4), December, 2021, pp. 15-25

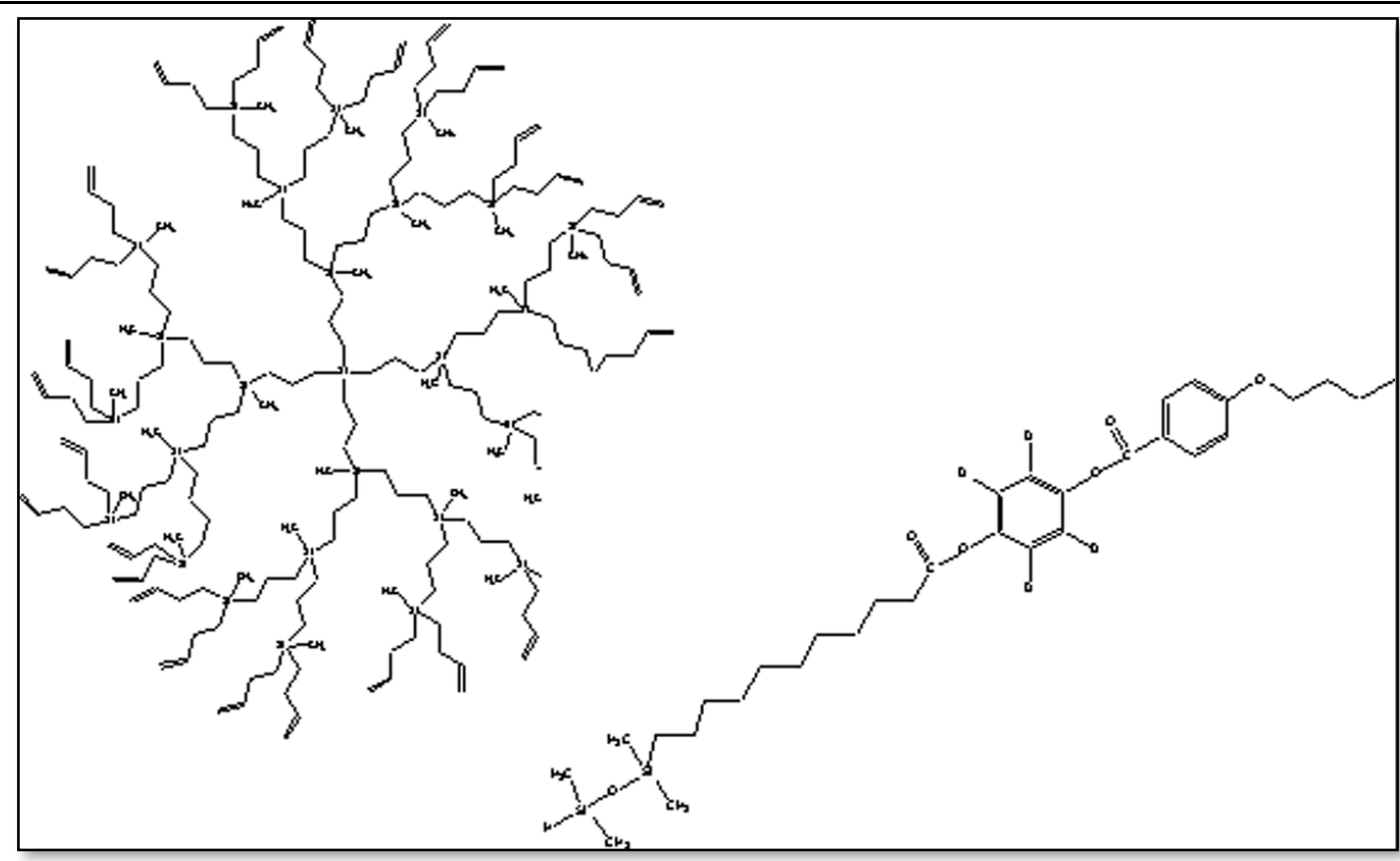

Figure 12. Showing 3rd generation dendritic core and one of 32 mesogenic units with a flexible spacer. In the liquid crystal dendrimer, the terminal $\mathrm{Si}$ atom of a mesogenic unit is joined to every extremal double bonded $\mathrm{C}$ atom on the core.

\section{Conclusion}

A common feature of all dendrimers considered in this review, possessing liquid crystal properties due to various factors, is that anisotropic mesophases are formed only in cases when a dendrimer molecule is sufficiently flexible and may readily deform to acquire a spherical shape in the mesophase.

\section{References}

[1] Astruc D.; Boisselier E. and Ornelas C.; "Dendrimers designed for functions: from physical, photophysical, and supramolecular properties to applications in sensing, catalysis, molecular electronics, photonics, and nanomedicine". Chemical Reviews. 110(4): 1857-959, April, 2010).

[2] Fre'chet J.M.J. and Tomalia D.A.; editors, "Dendrimers and other dendritic Polypolymers". Chichester, John Wiley \& Sons, Ltd, 2001.

[3] Buhleier E.; Wehner W. and Vogtle F.; "Cascade- and Nonskid-Chain-like Syntheses of Molecular Cavity Topologies". Synthesis. 1978(2): 155-158, 1978.

[4] Ranta V.P.; Mannermaa E. and Lummepuro K.; "Barrier analysis of periocular drug delivery to the posterior segment". Journal of Controlled Release; 148(1): 42-48, 2010.

[5] Mathias C.J.; Wang S.; Waters D.J. and Turek J.J.; "Low P.S.; Green M.A.; Indium-111-DTPA-folate as a potential folate-receptor-targeted radiopharmaceutical". J Nucl Med.; 39(9): 1579-1585, 1998.

[6] Grayson S.M. and Frechet J.M.J.; "Convergent dendrons and dendrimers: from synthesis to applications". Chem Rev, 101: 3819-3868, 2001.
[7] Dorski C.M.; Doyle F.J. and Peppas N.A.; "Preparation and characterization of glucose- sensitive P(MAA-gEG) hydrogels". Polym. Mater. Sci. Eng. Proc.; 6(1): 281-282, 1997.

[8] Miller L.L.; Duan R.G.; Tully D.C. and Tomalia D.A.; "Electrically conducting dendrimers". J. Am. Chem. Soc.; 119(92): 1005-1010, 1997.

[9] Holister P.; Christina R.V. and Harper T.; "Dendrimers: Technology White Papers". Cientifica, 2010.

[10] Gregory F. and Kakkar A.K.; "Diels-Alder "Click" Chemistry in Designing Dendritic Macromolecules". Chem. Eur. J.; 15(23): 5630-5639, 2009.

[11] Percec V.; Chu P.; Ungar G. and Zhou J.; "Rational design of the first $\mathrm{n}$ onspherical dendrimer which displays calamitic nematic and smectic thermotropic liquid crystalline phases". J Am Chem Soc; 117: 11441-54, 1995.

[12] Lorenz K.; Ho“lter D.; Stu“hn B.; Mu“lhaupt R. and Frey H.; "A mesogenfunctionalized carbosilane dendrimer: a dendritic liquid crysytalline polymer". Adv Mater; 8:414-6, 1996.

[13] Ponomarenko S. A.; Rebrov E.A.; Bobrovsky A. Y.; Boiko N. I.; Muzafarov A. M. and Shibaev V. P.; "Liquid crystalline carbosilane dendrimers: first generation". Liq Cryst; 21: 1-12, 1996.

[14] Barbera' J.; Gime'nez R.; Marcos M. and Serrano J. L.; "Dendrimers with laterally grafted mesogens". Liq Cryst; 29: 309-14, 2002.

[15] Cameron J. H.; Facher A.; Lattermann G. and Diele S.; "Poly (propyleneimine) dendromesogens with hexagonal columnar mesophase". Adv Mater; 9: 398403, 1997. 


\section{Al-Nahrain Journal of Science}

ANJS, Vol.24 (4), December, 2021, pp. 15-25

[16] Meier H.; Lehmann M. Stilbenoid dendrimers. Angew Chem Int Ed; 37: 643-5, 1998.

[17] Busson P.; Ihre H. and Hult A.; "Synthesis of a novel dendritic liquid crystalline polymer showing a ferroelectric SmC* phase". J Am Chem Soc; 120: 9070-1, 1998.

[18] Zhoua, Q.; Wu, Y.; Sun, Y.; Sheng, X.; Tong, Y.; Guo, J. and Zhao, J.; "Magnetic polyamidoamine dendrimers for magnetic separation and sensitive determination of organochlorine pesticides from water samples by high-performance liquid chromategraphy". Journal of Environmental Sciences, 102: 6473, 2021.

[19] Li J.; Liang H.; Liu J. and Wang Z.; "Poly (amidoamine) (PAMAM) dendrimer mediated delivery of drug and pDNA/siRNA for cancer therapy". International journal of pharmaceutics, 546(1-2): 215-225, 2018.

[20] Aya S.; Haba O.; Yonetake K. and Araoka, F. "Anchoring and molecular conformation of liquid crystalline dendrimer". Journal of Molecular Liquids, 321, 114379, 2021.

[21] Li W.; Dohi T.; Hara M.; Nagano S.; Haba O.; Yonetake K. and Seki T.; "Phototriggeredmass migration consorted with surface dewetting in thin films of a liquid crystalline azobenzene-containing dendrimer". Macromolecules 45: 6618-6627, 2012.

[22] Nádasi H.; Stannarius R.; Eremin A.; Ito A.; Ishikawa K.; Haba O.; Yonetake K.; Takezoe H. and Araoka F.; "Photomanipulation of the anchoring strength using a spontaneously adsorbed layer of azo dendrimers". Phys. Chem. Chem. Phys.; 19: 7597-7606, 2017.

[23] Aya S.; Hikima T.; Haba O.; Yonetake K. and Araoka F.; "Dynamics of phototunable twodimensional polar wetting sheets of a dendritic liquid crystal". Phys. Rev. E 98, (52701-1-7), 2018.

[24] Shvetsov S. A.; Emelyanenko A. V.; Boiko N. I.; Zolotko A.S.; Zhang Y.-S.; Liu J.-H. and Khokhlov A.R.; "Optical orientation of nematic liquid crystal droplets via photoisomerization of an azodendrimer dopant". Beilstein J. Nanotechnol.; 9: 870-879, 2018.

[25] Noh J.; Jampani V. S. R.; Haba O.; Yonetake K.; Takezoe H. and Lagerwall J. P. F.; "Sub-second dynamic phototuning of alignment in azodendrimerdoped nematic liquid crystal shells". J. Mol. Liq.; 267: 197-204, 2018.

[26] Momoi Y.; Kwak M.; Choi D.; Choi Y.; Jeong K.; Koda T.; Haba O.; Yonetake K.; "Polyimide-free LCD by dissolving dendrimers". J. Soc. Inf. Disp.; 20: 486492, 2012.

[27] Haba O.; Kitade D.; Takahashi K.; Matsuno W.; Itabashi H.; Koda T.; Yonetake K.; Kwak M.; Momoi Y.; Kim N.; Hong S.; Kang D. and Choi Y.; "Homeotropic alignment of a linear polyacrylate having a side chain consisting of a 1 st generation polypropyleneimine dendron with peripheral cyclohexylphenyl mesogens". Mol. Cryst. Liq. Cryst.; 610: 122-128, 2015.

[28] Iguarbe V.; Barberá J. and Serrano J. L.; "Functional Janus dendrimers containing carbazole with liquid crystalline, optical and electrochemical properties". Liquid Crystals, 47(2): 301-308, 2020.

[29] Gracia I.; Serrano J. L.; Barberá J.; et al.; "Functional organogelators formed by liquid-crystal carbazolecontaining bis-MPA dendrimers". RSC Adv.; 6(46): 39734-39740, 2016.

[30] Gracia I.; Feringan B.; Serrano J.L.; et al.; "Functional carbazole liquid-crystal block codendrimers with optical and electronic properties". Chem Eur J.; 21(3): 1359-1369, 2015.

[31] Rosen B. M.; Wilson C. J.; Wilson D. A.; et al. "Dendronmediated self-assembly, disassembly, and self-organization of complex systems". Chem Rev.; 109(11): 6275-6540, 2009.

[32] Turrin C. O.; Manoury E. and Caminade A. M. "Ferrocenyl phosphorhydrazone dendrimers synthesis, and electrochemical and catalytic properties". Molecules, 25(3): 447, 2020.

[33] Caminade, A. M.; Turrin, C. O.; Laurent, R.; Ouali, A. and Delavaux-Nicot, B.; "Dendrimers: Towards Catalytic, Material and Biomedical Uses"; John Wiley \& Sons Ltd.: Chichester, UK; 1-538, 2011.

[34] Lyu, Z.; Ding, L.; Huang, A. T.; Kao, C. L. and Peng, L.; "Poly (amidoamine) dendrimers: Covalent and supramolecular synthesis". Materials Today Chemistry, 13: 34-48, 2019.

[35] Tomalia D. A.; Baker H.; Dewald J.; Hall M.; Kallos G.; Martin S.; Roeck J.; Ryder J. and Smith P.; "A new class of polymers: starburst-dendritic macromolecules", Polym. J. 17(1): 117e132, 1985.

[36] Wu J.; Zhou J.; Qu F.; Bao P.; Zhang Y. and Peng L.; "Polycationic dendrimers interact with RNA molecules: polyamine dendrimers inhibit the catalytic activity of Candida ribozymes", Chem. Commun. 3 313e315, 2005.

[37] Concellón A.; Liang T.; Schenning A. P.; Serrano J. L.; Romero P. and Marcos M.; "Proton-conductive materials formed by coumarin photocrosslinked ionic liquid crystal dendrimers". Journal of Materials Chemistry C, 6(5): 1000-1007, 2018.

[38] Högberg D.; Soberats B.; Yoshio M.; Mizumura Y.; Uchida S.; Kloo L.; Segawa H. and Kato T.; Chem Plus Chem, 82, 834. 19, 2017.

[39] Eremin A.; Nádasi H.; Hirankittiwong P.; Kiang-Ia J.; Chattham N.; Haba O. and Takezoe $\mathrm{H}$. "Azodendrimers as a photoactive interface for liquid crystals". Liquid Crystals, 45(13-15): 2121-2131, 2018.

[40] Ichimura K.; Suzuki Y.; Seki T.; et al.; "Reversible change in alignment mode of nematic liquid crystals regulated photochemically by command surfaces modified with an azobenzene monolayer". Langmuir.;4: 1214-1216, 1988. 


\section{Al-Nahrain Journal of Science}

ANJS, Vol.24 (4), December, 2021, pp. 15-25

[41] Gibbons W. M.; Shannon P. J.; Sun S. T.; et al.; "Surface mediated alignment of nematic liquid crystals with polarized laser light". Nature.; 351: 4950, 1991.

[42] Li W.; Dohi T.; Hara M.; et al.; "Phototriggered mass migration consorted with surface dewetting in thin films of a liquid crystalline azobenzene-containing dendrimer". Macromolecules.;45: 6618-6627, 2012.

[43] Jber N. R. and Salman S. A.; "Liquid crystalline dendrimer: Sythesis and Chracterization". Baghdad Science Journal, 11, 2014.

[44] Yan Z. M.; Yong S. W.; Yuan Z. G.; Shan W. and Nai N. G.; "Synthesis and Properties of Dendrimer Liquid Crystal Based on Ester and Ether of Gallic Acid". Adv. Mater. Res.; 554: 60-64, 2012.

[45] Richardson, R. M.; Hanna, S.; Brooks, N. J.; Gauthe, B. L. L. E.; Pizzey, C.; Agina, E. and Shibaev, V. P. "Columnar phases in liquid crystal dendrimers: variable pressure x-ray diffraction". Molecular Crystals and Liquid Crystals, 541(1): 177-415, 2014.

[46] Richardson, R. M.; Agina, E. V.; Boiko, N. I.; Shibaev, V. P. and Grillo, I.; Journal of Physical Chemistry B, 112: 16346-16356, 2008. 